\title{
Avaliação no ensino fundamental das escolas públicas da rede municipal de Jaguarão-RS
}

\author{
Evaluación en la enseñanza primaria de las escuelas públicas de la
} red municipal de educación Yaguarón-RS

Evaluation in primary education of the public schools of the municipal educational network of Jaguarão-RS

\author{
Rosa Maria Martins Carvalho Dutra ${ }^{1}$ \\ Maria Alice de Freitas Sias ${ }^{2}$ \\ Santiago Bretanha ${ }^{3}$ \\ Ana Cristina da Silva Rodrigues ${ }^{4}$
}

\begin{abstract}
Resumo
A avaliação pode ser considerada como ponto fundamental no que diz respeito ao processo de ensinoaprendizagem, permitindo-nos elencar subsídios para que os docentes direcionem sua prática, as escolas reestruturem seus projetos pedagógicos, os sistemas de ensino definam políticas públicas para que se invista na educação para o sucesso. Faz-se necessária uma avaliação que pressuponha acompanhamento individualizado, em vistas de evitar a evasão escolar e a repetência, que verifique o rendimento escolar de forma continua e formativa levando em consideração a realidade local e os indicadores de cada escola em particular. Este trabalho objetiva investigar as características da avaliação utilizada no município de Jaguarão relacionando essas aos documentos oficiais - Plano Municipal de Educação (Lei nº 13.005/2014) e Plano Nacional de Educação. Diante disso, a pesquisa pretende propor, por meio de projeto de intervenção no âmbito da Secretaria Municipal de Educação, uma avaliação que auxilie a gestão escolar a melhorar os rumos da educação no município, para que alcance os índices estabelecidos pelo IDEB. O projeto está sendo desenvolvido nas escolas da rede municipal de ensino de Jaguarão, especificamente com a participação dos supervisores das Escolas de Ensino Fundamental e professores de Língua Portuguesa - anos finais. Esta pesquisa, metodologicamente, é do tipo intervenção pedagógica, uma vez que trabalha com dados gerados pelo estudo, busca como produto final a mudança e nasce da necessidade de dialogar com a teoria. A metodologia para coleta e análise de dados parte de uma abordagem qualitativa.
\end{abstract}

Palavras-Chave: Avaliação, aprendizagem, ensino fundamental.

\section{Resumen}

La evaluación suele considerarse cómo punto fundamental en lo que dice respeto al proceso de enseñanzaaprendizaje, permitiéndonos listar subsidios para que los docentes dirijan sus prácticas, las escuelas

\footnotetext{
${ }^{1}$ Mestranda em Educação pelo Programa de Pós-Graduação em Educação da Universidade Federal do Pampa (PPGE/UNIPAMPA), campus Jaguarão; Jaguarão, Rio Grande do Sul, Brasil; rosadutra14@ gmail.com.

${ }^{2}$ Mestranda em Educação pelo Programa de Pós-Graduação em Educação da Universidade Federal do Pampa (PPGE/UNIPAMPA), campus Jaguarão; Jaguarão, Rio Grande do Sul, Brasil; alicesias @ yahoo.com.br.

${ }^{3}$ (COLABORADOR) Mestrando em Letras pelo Programa de Pós-graduação em Letras da Universidade Católica de Pelotas (PPGL/UCPEL); Pelotas, Rio Grande do Sul, Brasil. santiagobretanha@gmail.com. Bolsista Prosuc I/CAPES.

${ }^{4}$ (COLABORADORA) Doutora em Educação; Professora Adjunta do Programa de Pós-Graduação em Educação da Universidade Federal do Pampa (PPGE/UNIPAMPA), campus Jaguarão; Jaguarão, Rio Grande do Sul, Brasil; anacristina@unipampa.edu.br.
} 
reestructuren sus proyectos pedagógicos, los sistemas de enseñanza definan políticas públicas para que se invierta en la educación a fines de suceso. Se hace necesaria una evaluación que presuponga acompañamiento individualizado, en vistas de evitar la evasión escolar y la repitencia, que verifique el rendimiento escolar de manera continua y formativa teniendo en consideración la realidad local y los indicadores de cada escuela en particular. Este trabajo tiene por objetivo examinar las características de la evaluación empleada en el municipio de Yaguarón relacionando esas a los documentos oficiales - Plano Municipal de Educação (Lei $n^{\circ}$ 13.005/2014) y Plano Nacional de Educação. Delante de eso, la investigación pretende proponer por medio de proyecto de intervención en el ámbito de la Secretaria Municipal de Educação una evaluación que auxilie la gestión escolar a mejorar los rumbos de la educación en el municipio, para que alcance los índices del IDEB. El proyecto está en proceso de desarrollo en las escuelas de la red municipal de enseñanza de Yaguarón, específicamente con la participación de los supervisores de las escuelas de enseñanza primaria y los profesores de lengua portuguesaaños finales. Esta investigación, metodológicamente, es del tipo de intervención pedagógica, una vez que trabaja con dados generados por el estudio, busca como producto final el cambio y nasce de la necesidad de dialogar con la teoría. La metodología para colecta de datos parte de un abordaje cualitativo.

Palabras clave: Evaluación, Aprendizaje, Enseñanza Primaria.

\begin{abstract}
Evaluation is considered as a fundamental element in the teaching-learning process, allowing us to list subsidies for teachers to direct their practices, schools to restructure their pedagogical projects, school systems to define public policies for investing in an education for success. Is necessary an evaluation that presupposes individualized support, in order to avoid school evasion and repetition that verifies the school performance in a continuous and formative way, taking into account the local reality and the indicators of each school in specific. This work aims to examine the characteristics of the evaluation used in the municipality of Jaguarão relating these to the official documents - Plano Municipal de Educação (Lei $\left.n^{o} 13.005 / 2014\right)$ and Plano Nacional de Educação. In view of this, the research aims to propose, through an intervention project within the Municipal Secretary of Education, an evaluation that helps school management to improve the courses of education in the municipality, so that it reaches the IDEB indexes. The project is under development in the schools of the Jaguarão municipal education network, specifically with the participation of primary school supervisors and portuguese language teachers - final years. This research, methodologically speaking, is of the type of pedagogical intervention, once it works with data generated by the study, it aims change as a final product and arises from the need to dialogue with theory. The methodology for data collection is based on a qualitative approach.
\end{abstract}

Key words: Evaluation, Learning, Primary Education.

\title{
1. Introdução
}

O presente texto é um recorte dos estudos do projeto de intervenção que tem como título "Um Olhar sobre a Avaliação do Ensino Fundamental nas Escolas Públicas da Rede Municipal de Jaguarão-RS", cujo objetivo geral é refletir e analisar os questionamentos dentro do processo de avaliação, de forma que possamos entender o que está sendo feito pelo aluno, analisando: como ele chegou ao erro ou ao acerto; que aspectos encontram-se por trás disso; que medidas podem ser adotadas para que possamos garantir qualidade de ensino sem levar em conta os resultados obtidos nas notas e sim, ressaltando, o meio utilizado pelo aluno para aquisição dos conhecimentos. Desse modo, em nossa visão, avaliação presume uma ótica formativomediadora e não classificatória, que contempla a verificação do rendimento escolar de forma contínua e formativa e que leva em consideração objetivos de aprendizagem com base na idade, competências e critérios de interesse do processo de ensino. Segundo Antunes (2004, p. 28), 
[...] ao refletir sobre o tipo de avaliação que pretendemos desenvolver, temos que estar conscientes de que os alunos também estão atribuindo um sentido a essa avaliação e que esta depende da maneira como a atividade é proposta, de como nos envolvemos a ela como professores e de como a avaliamos.

A partir de 1995, no Brasil, foi consolidado o SAEB - Sistema de Avaliação da Educação Básica - com o objetivo de verificar as competências de leitura e solução/resolução de problemas de alunos do $4^{\circ}$ ano e do $8^{\circ}$ ano e alunos $3^{\circ}$ ano do ensino médio, o que mostraria a "qualidade da educação básica". Em 2005, inicia-se a Prova Brasil, aplicada aos alunos dos $4^{\circ}$ e $8^{\circ}$ anos, adotando para isso os descritores do SAEB de acordo com as relações idade/série.

Todas essas avaliações nacionais têm nos permitido obter maiores dados sobre a situação da educação no Brasil, assim como, em uma dimensão polêmica, proporciona amplas discussões sobre suas metodologias de aplicação, acerca da própria finalidade dos instrumentos de avaliação em larga escala e sobre os resultados obtidos nos diferentes níveis de ensino segundo os índices gerados por essas avaliações.

Diante dessas questões, em nossas perspectivas, a escola não deve permitir que os resultados das provas sejam interpretados como meros diagnósticos, pois o professor, através de uma pedagogia interativa, sabe perfeitamente da participação e produtividade de cada aluno. O mesmo é válido para as avaliações locais, no contexto da escola e da sala de aula: as provas, assim como os demais instrumentos avaliativos, não devem ser entendidas como simples formalidade do sistema escolar, ainda que elas impliquem inúmeros cuidados formais, sobre tudo em sua aplicação.

Defendemos que a avaliação, bem aplicada, é a via efetiva para sucesso escolar dos alunos. Para tanto, é importante que novos rumos sejam encontrados para medir a qualidade do aprendizado, proporcionando reflexões de por que o aluno não aprendeu, quais encaminhamentos adotar diante disso para, então, ressignificar a prática e, a partir daí, construir uma prática que se adapte constantemente à realidade.

Nesse sentido, Luckesi (2011, p. 20) afirma que,

[..] para que a avaliação seja possível e faça sentido, o primeiro passo é estabelecer e ter uma ação claramente planejada e em execução, sem o que a avaliação não tem como dimensionar-se e ser praticada, pois que o seu mais profundo significado, a serviço da ação, é oferecer-lhe suporte, com o objetivo de efetivamente chegar aos resultados desejados.

De todo modo, o processo avaliativo é ligado a uma grande preocupação por parte dos professores, a de atribuir notas que aprovam ou reprovam os alunos. Essa insegurança, ainda que justificada, é decorrente da necessidade de um redirecionamento pedagógico, de uma nova 
tomada de decisões. Nesse sentido, é preciso adotar meios para se fazer uma avaliação de forma contextualizada - enriquecendo o contexto educacional - e uma avaliação que não seja punitiva, classificatória, excludente e/ou seletiva. Nas palavras de Hoffmann (2006), a avaliação escolar, hoje, somente faz sentido se possuir a finalidade de buscar aberturas para a melhor aprendizagem.

Assim sendo, conforme Luckesi (2011, p. 429) oferecer ensino a educandos e reproválos são atos contraditórios. Quem ensina tem como objetivo o aprendizado do outro. A reprovação aposta no ato de ensinar e de aprender. Caso queiramos uma aprendizagem satisfatória e de qualidade, não há razão para que nossos alunos sejam, simplesmente, "reprovados". Nosso objetivo deve ser a aprendizagem e o desenvolvimento de nossos alunos; as notas, repetindo, são formalizações de um processo, não o seu todo, ou o seu fim.

A avaliação, em nossa perspectiva, deve ter como função fundamental permitir que a regulação das aprendizagens possa acontecer, possibilitando aos professores e equipes diretivas, pensar em didáticas que oportunizem a implementação de uma pedagogia diferenciada, visando garantir aos alunos a continuidade de seus processos de aprendizagem, ou, melhor, que sirva de processo de aprendizagem a toda a comunidade escolar. Segundo Hoffmann,

\footnotetext{
O conhecimento do aluno vem dos objetos e cabe ao professor organizar os estímulos com os quais o aluno entrará em contato para aprender. A prática pedagógica consistirá, então, na transmissão clara e explícita dos conteúdos pelo professor, apresentando exemplos preferentemente concretos (organização de estímulos). Essa situação, por si só, promoverá a aprendizagem, desde que o aluno entre em contato com tais estímulos, esteja atento às situações. (HOFFMANN, 1994, p. 54)
}

Diante do exposto, surge a necessidade de pensar em um instrumento que busque caminhos e estratégias para melhorar o processo de avaliação das escolas. Aqui, na perspectiva de docentes, inseridos na gestão escolar e/ou na pesquisa em educação, lançamos um olhar de fora para dentro do processo educacional do município de Jaguarão. Em que o "fora" são as lentes do pesquisador que olha para o "dentro" de sua própria realidade.

Desse modo, a pesquisa pretende propor, por meio de projeto de intervenção no âmbito da Secretaria Municipal de Educação, modelos de uma avaliação que auxiliem a gestão escolar a melhorar os rumos da educação no município, para que esta alcance os índices estabelecidos pelo IDEB. O projeto, em fase de aplicação, está sendo desenvolvido nas escolas da rede 
municipal de ensino de Jaguarão, especificamente com a participação dos supervisores das Escolas de Ensino Fundamental e professores de Língua Portuguesa - anos finais. ${ }^{5}$

\section{Metodologia}

A presente pesquisa assume abordagem de intervenção pedagógica que, segundo os postulados de Damiani et al. (2013, p. 58) são “[...] investigações que envolvem o planejamento e a implementação de interferências (mudanças, inovações) - destinadas a produzir avanços, melhorias, nos processos de aprendizagem dos sujeitos que delas participam". Assim, se trabalha com dados gerados pelo estudo e se busca como produto final a mudança de um determinado cenário educacional em que os sujeitos-pesquisadores são-estão inseridos.

Diante de uma necessidade ontológica de diálogo com a teoria, se constrói uma metodologia embasada em uma coleta e análise de dados, sendo parte em caráter qualitativo, que Oliveira (2009) caracteriza como uma pesquisa que possui um caráter hermenêutico, pois pauta-se na tarefa de pesquisar sobre a experiência vivida dos seres humanos.

O cenário que a pesquisa retrata e pretende realizar uma intervenção é o município de Jaguarão, localizado ao sul do Rio Grande do Sul, fronteira com o município de Rio Branco Uruguai. A cidade possui cerca de vinte e sete mil habitantes, quinze escolas (estaduais e municipais) localizadas no perímetro urbano.

O projeto foi elaborado considerando a maneira como a avaliação é compreendida no Ensino Fundamental da Rede Municipal de Jaguarão, em uma abordagem qualitativa de investigação. Frente a isso, atentamos à compreensão das complexidades inerentes à realidade educacional, identificando quais procedimentos de intervenção pedagógica e administrativa precisam acontecer para uma melhor qualidade de ensino sob a concepção de "avaliação formativa", construída com os diferentes sujeitos da educação. Segundo Villas Boas (2001)

[...] a avaliação formativa contribui para que os alunos aprendam a aprender, porque os ajuda a desenvolver as estratégias necessárias; coloca ênfase no processo de ensino e aprendizagem, tornando os alunos participantes desse processo; possibilita a construção de habilidades de auto-avaliação e avaliação dos colegas; ajuda os alunos a compreenderem a sua própria aprendizagem.

Com base nos escritos de Villas Boas, Luckesi e Hoffmann, primeiramente, voltamonos ao estado da arte do objeto-conceito "avaliação", estudo que serviu para elaboração de um

\footnotetext{
${ }^{5}$ E, aqui, desdobra-se com a cooperação entre duas pesquisadoras do Programa de Pós-graduação em educação da UNIPAMPA e de um pesquisador do Programa de Pós-graduação em Letras/Linguística Aplicada da Universidade Católica de Pelotas.
} 
diagnóstico base para a definição de metas, estratégias e indicadores para a estruturação dos instrumentos de coleta de dados e sua conseguinte avaliação. A partir dessa revisão bibliográfica, construímos como instrumento de coleta de dados questionários semiestruturados. Com esses, buscamos, junto à escola, um levantamento dos índices de aprovação/reprovação e como os educadores compreendem e realizam o processo de avaliação em sala de aula. Tal questionários,

Revelam análises pessoais mais aprofundadas do que os grupos de foco; Respostas são atribuídas diretamente a um entrevistado específico, diferentemente dos grupos de foco, onde é difícil determinar qual entrevistado deu uma resposta em particular; Devido à redução da pressão social causada nos grupos de foco, nas entrevistas individuais há livre troca de informações é maior; Maior flexibilidade na condução da entrevista, já que não existem as restrições necessárias para se conduzir um trabalho em grupo. (FREITAS, 2013, p. 78)

A partir da análise dos dados, seguimos à etapa interventiva. Para que seja possível pensar em uma "nova forma de avaliação" no município que pretende-se mobilizar toda comunidade escolar, para - através de amplos debates - se chegue a um produto final: a elaboração de um documento que servirá para definição de metas e estratégias voltadas a aprimorar a avaliação e ao fortalecimento da educação do município.

O trabalho ainda está em andamento, mas, até o momento, com vistas a alcançar o nosso propósito, estão sendo organizados encontros com as supervisoras das Escolas de Ensino Fundamental de Jaguarão e professoras de Língua Portuguesa - anos finais ( $8^{\circ}$ e $9^{\circ}$ anos). Nesse ínterim, em um primeiro momento foi apresentada a proposta do projeto para grupo e, na sequência, estão sendo problematizadas e levantadas discussões sobre a avaliação e suas diferentes concepções. O Processo culminará com a redação do documento, em suas metas e estratégias.

\section{Discussões}

Frente à breve introdução, os objetivos e procedimentos metodológicos acima apresentados, a pesquisa assume como referencial teórico as reflexões de Hoffman (2000), definindo e questionando os diferentes modelos de avaliação; Luckesi (2011) relacionando a avaliação com a aprendizagem na escola; Paro (2012) discutindo a gestão democrática na escola. Devido ao estudo ainda estar em fase de desenvolvimento, as discussões que trazemos são referentes ao estado da arte sobre algumas discussões sobre gestão democrática escolar o que resulta em um "novo" modelo de escola e, consequentemente, de avaliação. 
De modo geral, vemos que as escolas, tanto particulares como públicas, possuem uma organização para que seu funcionamento seja pleno e dê conta das demandas e obrigatoriedades da instituição. Tal organização se dá a partir da perspectiva teórica que a gestão segue, privilegiando espaços democráticos em que o diálogo se dá em todas as esferas ou hierárquicos, no qual "os superiores" emitem uma ordem e os acatam.

No Brasil, a gestão democrática da escola nasce em um momento de mudanças e de construção coletiva, fomentando discussões que repensavam o papel dos profissionais/educadores e o funcionamento de todos os setores da escola. De acordo com Brasil,

A gestão democrática pode ser considerada como meio pelo qual todos os segmentos que compõem o processo educativo participam da definição dos rumos que a escola deve imprimir à educação de maneira a efetivar essas decisões, num processo contínuo de avaliação de suas ações. (BRASIL, 2007, 34).

A partir desse conceito, vemos que a gestão democrática escolar representa um coletivo que se responsabiliza pelos rumos que a escola deve seguir. Tal coletivo é representado por todos os seus sujeitos que constituem a escola, a comunidade escolar e alunos, o qual decidem em conjunto todas as pautas, problemas e demandas. Libâneo (2013), divide a gestão escolar em dois tipos, a gestão técnico-cientifica ou democrático participativa, para o autor, a primeira hierarquiza os cargos e funções, visando a racionalidade do trabalho, já a segunda defende a tomada de decisões de maneira coletiva (LIBÂNEO, 2013, p. 89).

Dentro dessas duas visões, Paro (2006) faz uma crítica aos discursos promovidos pelos gestores, visto que a palavra participação é muito difundida no espaço escolar, entretanto, para o autor

\footnotetext{
O que nós temos hoje é um sistema hierárquico que pretensamente coloca todo o poder nas mãos do diretor. Não é possível falar das estratégias para se transformar o sistema de autoridade no interior da escola, em direção a uma efetiva participação de seus diversos setores, sem levar em conta a dupla contradição que vive o diretor de escola hoje. Esse diretor, por um lado, é considerado a autoridade máxima no interior da escola, e isso, pretensamente, lhe daria um grande poder e autonomia; mas, por outro lado, ele acaba se constituindo, de fato, em virtude de sua condição de responsável último pelo cumprimento da Lei e da Ordem na escola, em mero preposto pelo Estado. (Paro, 2006, p. 11)
}

Com base nesse posicionamento, vemos que há diferenças entre o que está, atualmente, sendo discutido teoricamente e o que acontece no interior das escolas. Com base nos escritos 
citados acima, vemos que a escola ${ }^{6}$ segue uma perspectiva técnico-cientifica, no qual as decisões são tomadas por um grupo restrito de professores e os demais componentes da escola devem acatar.

Partindo das duas definições de gestão escolar (LIBÂNEO, 2013), essa pesquisa segue os preceitos defendidos pela gestão democrático participativa, defendendo, no que se refere ao nosso campo de pesquisa, uma avaliação que seja formativa e abdique das, chamadas por Hoffman (2000), avaliações tradicionais. Para a autora,

As notas e provas funcionam como redes de segurança em termos de controle exercido pelos professores sobre seus alunos, da escola e dos pais sobre os professores, do sistema sobre suas escolas. Controle esse que parece não garantir o ensino de qualidade que pretendemos, pois as estatísticas são cruéis em relação à realidade das nossas escolas. (HOFFMANN, 2003, p.16).

Logo, como já foi abordado anteriormente, essa pesquisa pretende propor, por meio de projeto de intervenção no âmbito da Secretaria Municipal de Educação, modelos de uma avaliação que auxiliem a gestão escolar a melhorar os rumos da educação no município, para que esta alcance os índices estabelecidos pelo IDEB. Desse modo, se segue um modelo de avaliação que cria possibilidades dos alunos participarem do processo avaliativo ativamente e, assim, compreenderem o seu real significado.

A avaliação, enquanto relação dialógica, vai conceber o conhecimento como apropriação do saber pelo aluno e também pelo professor, como ação-reflexão-ação que se passa na sala de aula em direção a um saber aprimorado, enriquecido, carregado de significados, de compreensão. Dessa forma, a avaliação passa a exigir do professor uma relação epistemológica com o aluno - uma conexão entendida como reflexão aprofundada a respeito das formas como se dá a compreensão do educando sobre o objeto do conhecimento. (HOFFMANN, 1994, p. 56).

A partir desse arquétipo, se evidencia a importância das gestões reavaliarem o seu posicionamento, a fim de tornarem-se democráticas participativas e acompanharem os adventos da sociedade contemporânea. Para Paro (2006, p. 12) uma gestão democrática com vistas a objetivos transformadores só desempenhará um papel progressista se tiver acompanhada de um coletivo (comunidade escolar), pois, assim, todos terão oportunidade de debater e discutir os problemas da escola e pensar soluções e encaminhamentos em conjunto.

\footnotetext{
${ }^{6}$ Ressaltamos que nesse trabalho não estamos nos referindo a uma escola específica, assim como também não sabemos a partir de que contexto Paro (2006) se posiciona, estamos, somente, nos valendo dos escritos do autor para discutir e refletir sobre a nossa proposta.
} 


\section{Conclusões}

Esse projeto é um grande desafio, pois objetiva propor, junto às comunidades escolares e gestão municipal, novas formas de avaliação que contemplem caráter qualitativo acima, mas não em detrimento, do quantitativo. Qualitativa no sentido de avaliação que acompanhe a aprendizagem de cada aluno, e, assim, seja possível alcançar o caráter qualitativo expresso em índices.

Desse modo, o presente trabalho, além de discutir sobre a escola enquanto espaço democrático que prioriza o diálogo entre todos os que estão envolvidos a ela, apresenta uma proposta, em andamento, de intervenção pedagógica, colabora com a educação no município de Jaguarão, de modo a propor uma readequação da proposta pedagógica referente às metodologias de avaliação, assim como informa dados, em sentido amplo, sobre o desempenho e os resultados alcançados pelos atuais sistemas de ensino/avaliação. Assim, em nosso trabalho, a avaliação presta ao papel de compreender o aluno, buscando desafiar suas capacidades de modo a garantir autonomia moral e intelectual (HOFFMANN, 2000), configurando-se como um instrumento que reconduz os processos educativos em um processo orgânico, tal qual salienta boa parte dos Projetos Políticos Pedagógicos das escolas de Jaguarão, isto é, a avaliação é fundamental para o planejamento das práticas docentes e gestoras e para o diagnóstico de seus efetivos impactos.

A proposta que aqui apresentamos surge no sentido de instrumentalizar os professores para questionar, compreender e desnaturalizar a avaliação em vias de entender que "a passagem pela escola só tem sentido quando se supõe que se sairá dela diferentemente da forma como nela se entrou. $\mathrm{O}$ aproveitamento escolar, desta maneira nada mais é do que a apropriação que se faz daquilo que a escola pretende ensinar" (GATTI, 2015, p. 47).

\section{Referências}

BRASIL. Plano Nacional de Educação. 2001. Disponível em:

<http://portal.mec.gov.br/arquivos/pdf/pne.pdf>; acesso em: 10/05/2016.

BRASIL. Lei de Diretrizes e Bases da Educação Nacional. Lei no 9.394/96. Disponível em: <http://portal.mec.gov.br/arquivos/pdf/pne.pdf>; acesso em: 12/05/2016.

DAMIANI, M. F.; et al. Discutindo pesquisas do tipo intervenção pedagógica. Disponível em: < https://periodicos.ufpel.edu.br/ojs2/index.php/caduc/article/view/3822/3074>. Acesso em: 20 nov. 2017.

FREITAS, T. R. Metodologia de Pesquisa. Disponível em: < http://www2.dbd.pucrio.br/pergamum/tesesabertas/1112856_2013_cap_4.pdf>. Acesso em: 20 nov. 2017. 
GATTI, B. A. Problemas e Impasses da Avaliação de Projetos e Sistemas Educacionais: dois casos brasileiros.In: BROOK, N. (org.). A Avaliação da Educação Básica: a experiência brasileira. Belo Horizonte: Fino Traço, 2015, p. 46-60.

HOFFMANN, J. Avaliação Mediadora: Uma Prática da Construção da Pré-escola à Universidade. 17. ed. Porto Alegre: Mediação, 2000. 2000 . Avaliação: Mito e Desafio. Uma perspectiva construtivista. Porto Alegre: Mediação Avaliação mediadora: uma relação dialógica na construção do conhecimento. Ideias. São Paulo, nº 22, p. 5-9, 1994.

JAGUARÃO. Lei 6.151, de 25 de junho de 2015. Aprova o Plano Municipal de Educação (PME) e dá outras providências. Jaguarão: 2015. Disponível em:

<http://www.jaguarao.rs.gov.br>. Acesso em: 20 nov. 2017.

LIBÂNEO, José Carlos. Organização e gestão da Escola: teoria e prática. Goiânia: Alternativa, 2013.

LUCKESI, C. C. Avaliação da Aprendizagem Escolar: estudos e proposições.22. ed. São Paulo: Cortez, 2011.

OLIVEIRA, C. L. Um apanhado teórico-conceitual sobre a pesquisa qualitativa: tipos, técnicas características.Revista Travessias, v. 2, n. 3, p. 1-16, 2008.

PARO, V. H. Gestão Democrática da Escola Pública. 3. ed. São Paulo: Ática, 2012.

VILLAS BOAS, B. M. F. Avaliação Formatida e Formação de Professoraes: ainda um desafia. Disponivel em:

$<$ http://repositorio.unb.br/bitstream/10482/9269/1/ARTIGO_AvaliacaoFormativaFormacao.p df $>$. Acesso em: $15 \mathrm{dez} 2017$. 